\title{
Determination of the effective thermal conductivity of particulate composites based on $\mathrm{VO}_{2}$ and $\mathrm{SiO}_{2}$
}

\author{
Santiago Alvarez-Guerrero ${ }^{1}$, Jose Ordonez-Miranda ${ }^{2,3, *}$, Romeo de Coss ${ }^{1}$ and Juan Jose Alvarado-Gil ${ }^{1}$ \\ ${ }^{1}$ Departamento de Física Aplicada, Centro de Investigación y de Estudios Avanzados del I.P.N-Unidad Mérida, Carretera Antigua a \\ Progreso km. 6, A.P. 73 Cordemex, Mérida, Yucatán 97310, México. \\ ${ }^{2}$ LIMMS, CNRS-IIS UMI 2820, The University of Tokyo, Tokyo 153-8505, Japan. \\ ${ }^{3}$ Institute of Industrial Science, The University of Tokyo, Tokyo 153-8505, Japan. \\ *corresponding author: jose.ordonez@cnrs.pprime.fr
}

\begin{abstract}
The effective thermal conductivity of composites made up of $\mathrm{VO}_{2}\left(\mathrm{SiO}_{2}\right)$ spherical particles randomly distributed and embedded in a $\mathrm{SiO}_{2}\left(\mathrm{VO}_{2}\right)$ matrix are numerically studied in a range of temperatures around the metal-insulator transition of $\mathrm{VO}_{2}$. This is done by means of three-dimensional finite element simulations for different concentrations and sizes of the particles as well as various interface thermal resistances. Our results were validated against the Mori-Tanaka analytic model. In addition, we developed a numerical method to calculate the heat storage capacity for composites with $\mathrm{VO}_{2}$ particles dispersed into $\mathrm{SiO}_{2}$ matrix. It is shown that: i) The effective thermal conductivity of $\mathrm{VO}_{2} / \mathrm{SiO}_{2}$ composites increases with the $\mathrm{VO}_{2}$ particles' size, while the one of $\mathrm{SiO} / 2 / \mathrm{VO}_{2}$ composites is pretty much independent of the $\mathrm{SiO}_{2}$ particles' radius. ii) At the $\mathrm{VO}_{2}$ transition temperature $(342.5 \mathrm{~K})$, the effective thermal conductivity of $\mathrm{VO}_{2} / \mathrm{SiO}_{2}$ composites increases significantly at a rate of $2.7 \times 10^{-3} \mathrm{Wm}^{-1} \mathrm{~K}^{-2}$, such that its value doubles up the $\mathrm{SiO}_{2}$ matrix thermal conductivity at the particle concentration of $40.2 \%$. By contrast, the effective thermal conductivity of $\mathrm{SiO}_{2} / \mathrm{VO}_{2}$ composites decreases at a rate of $8.6 \times 10^{-3} \mathrm{Wm}^{-1} \mathrm{~K}^{-2}$. iii) The effective thermal conductivity is strongly affected by the thermal resistance in $\mathrm{VO}_{2} / \mathrm{SiO}_{2}$ composites, by contrast the resistance effect does not play an important role for particle volume fractions of $\mathrm{SiO}_{2}$ up to $34.1 \%$ in $\mathrm{SiO}_{2} / \mathrm{VO}_{2}$ composites. The Mori-Tanaka model and our simulations predict the same trend of the effective thermal conductivity values of $\mathrm{VO}_{2} / \mathrm{SiO}_{2}$ composites. However, the analytic model fails when the matrix is made up $\mathrm{VO}_{2}$ and the volumetric fraction exceeds $34.1 \%$ of $\mathrm{SiO}_{2}$. The latent heat storage capacity of $\mathrm{VO}_{2} / \mathrm{SiO}_{2}$ composites increases with the $\mathrm{VO}_{2}$ particles' concentration, such that at $40.2 \%$, it takes the value of $24553 \mathrm{~J} \mathrm{~kg}^{-1}\left(486.7 \mathrm{cal} \mathrm{mol}^{-1}\right)$, which is about half that of the pure $\mathrm{VO}_{2}$.
\end{abstract}

Keywords: particulate composites, effective thermal conductivity, interfacial resistance, vanadium dioxide. 


\section{Introduction}

The increasing demand for smaller and faster electronic, optoelectronic and thermal devices has created the need for design new materials. Additionally, industry has the need to adapt the physical properties of materials to desired specific applications. Composites are ideal candidates that can be used successfully to fulfill most of these requirements. Composites are mixtures of two or more types of materials (polymer, metal, ceramic, etc.) that form a new material with properties that are a combination of the components. Such materials are expected to have much improved properties compared to the initial matrix [1].

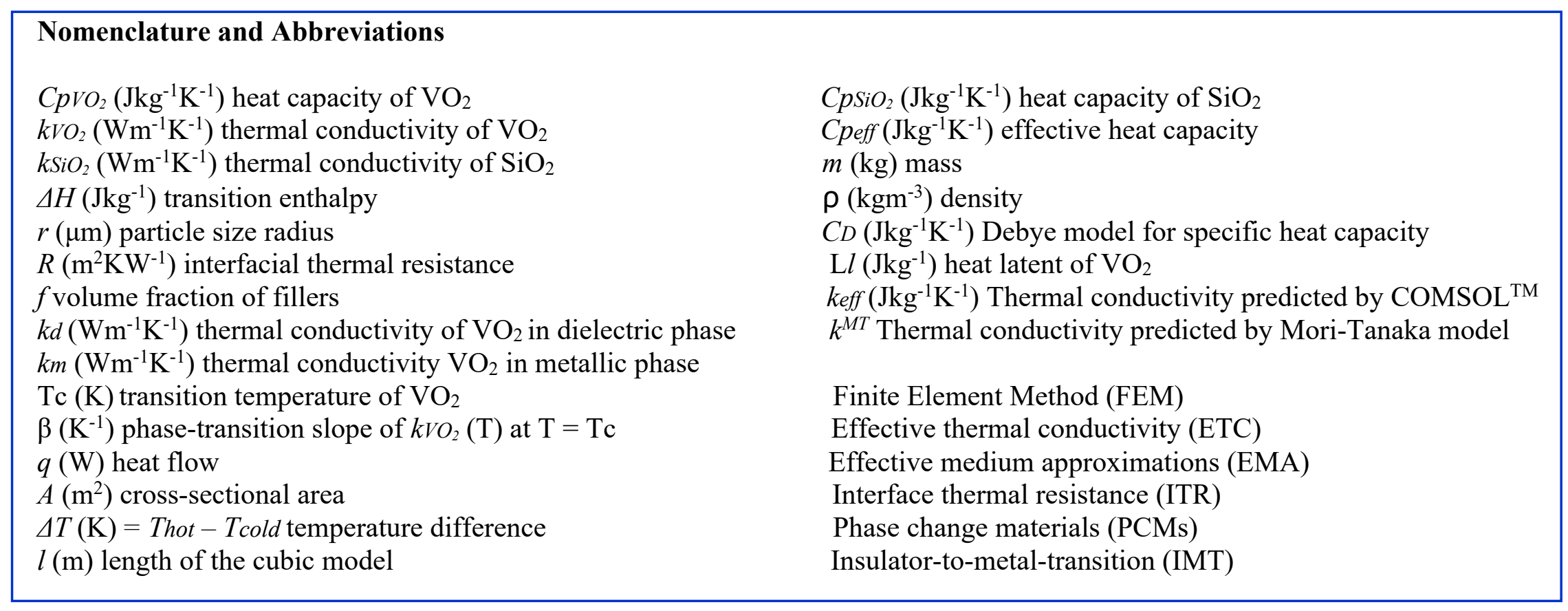

Particularly, phase change materials (PCMs) have been attracting the attention for the fabrication of novel composites due to their ability to adsorb/release thermal energy during the phase change process (e.g., solid to liquid, liquid to gas, solid to solid), which have shown to have numerous applications in the development of optical [2] and thermal switches [3] as well as in thermal storage energy applications [4,5]. This phase change has been observed in several metal oxides such as vanadium oxides $\left(\mathrm{VO}_{2}, \mathrm{~V}_{2} \mathrm{O}_{3}\right.$, etc.) [6,7], at different phase-transition temperatures. Particularly, $\mathrm{VO}_{2}$ has attracted much interest aimed to manipulate heat transfer due to its solid phase transition, involving a strong change of its thermal properties at temperatures near to room temperature [8]. At $68{ }^{\circ} \mathrm{C}$, $\mathrm{VO}_{2}$ changes from monoclinic (electrically insulating phase) to rutile tetragonal (metallic phase) [7] structure. 
In 1959, F. J. Morin observed the insulator-to-metal-transition (IMT) along the c direction in bulk crystals of vanadium dioxide induced upon heating at $\sim 68^{\circ} \mathrm{C}$ [7]. Since then, this near-room-temperature transition and its associated large optical and electrical properties changes have attracted the attention of researchers to employ $\mathrm{VO}_{2}$ in a wide variety of technological applications. Recent studies include: the development of energy-saving smart windows taking advantage of the infrared thermochromism induced by the IMT [9]. Manca et. al. presented a planar nanomechanical actuator based on $\mathrm{VO}_{2}$, this device is thermally activated through heating where the crystalline symmetry change associated with the IMT and its chevron-type design results in a large lattice expansion [10]. Prod'Homme et. al. employed $\mathrm{SiO}_{2}$ and $\mathrm{VO}_{2}$ as materials to theoretically design and study a near-field radiative thermal transistor, two silica semi-infinite plates playing the roles of the transistor collector and emitter while $\mathrm{VO}_{2}$ acts as a semitransparent base [11].

Cheng et. al. proposed a paraffin- $\mathrm{VO}_{2}$ phase change material (PCM) structure which consists of a solid-liquid paraffin phase change type material used as core, and the solid-solid $\mathrm{VO}_{2}$ (also PCM) used as shell [12]. This PCM structure showed a transition temperature of $58.2^{\circ} \mathrm{C}$, a fusion latent heat value of $163 \mathrm{Jg}^{-1}$ and a largely enhanced thermal conductivity $1.53 \mathrm{Wm}^{-1} \mathrm{~K}^{-1}$, which should be promising for the high-efficient thermal management applications. Muramoto et. al. has explored the application of novel $\mathrm{VO}_{2}$-glass materials, as a latent heat storage material [13].

Based on this background, we have explored theoretically the effective thermal conductivity of particulate composites structured by $\mathrm{VO}_{2}$ and $\mathrm{SiO}_{2}$. Oxide glasses generally exhibit high durability, in which their amorphous structure, without periodic ordering, demonstrates excellent formability and controllability [11]. These oxides are widely used in electronic and optical devices, and microelectromechanical systems [14]. Lopez et. al. [15] obtained experimentally vanadium dioxide single-crystals produced in an amorphous fused $\mathrm{SiO}_{2}$ host by means of stoichiometric co-implantation of vanadium and oxygen ions. Silica has proved to be an ideal host for $\mathrm{VO}_{2}$ due to its well-known thermal stability. Silicon does not dope $\mathrm{VO}_{2}$ since the $\mathrm{Si}^{4+}$ ion is too small to occupy the $\mathrm{VO}_{2}$ octahedral site $[16,17]$.

Numerous analytical expressions for estimation the effective thermal conductivity (ETC) of composite materials have been proposed [18-22]. Classical analytical models were developed by Maxwell and Rayleigh [18,19]. Maxwell was the first to give analytical expressions for effective conductivity of heterogenic medium [18] although considering the problem of dilute dispersion only. Rayleigh considered thermal interaction between particles, however, results from both approaches are very similar and losing accuracy for high volumetric fractions [19]. Hasselman and Johnson proposed a simple modification of the original Maxwell and Rayleigh models to derive the first expressions for effective thermal conductivity of composite materials with nonzero interfacial thermal resistance (ITR) [20]. However, the authors derived expressions for a continuous matrix phase with dilute concentrations only. Another scheme is the well-Known Lewis-Nielsen model [21], this empirical model gives relatively good results for the thermal conductivity of composites that reach even the maximum packing volume fraction of particles $(63.7 \%$ of random close packing of spheres); however, those equations do not include explicitly ITR. Various analytical methods, based on Homogenization Theories and Micromechanics have been applied to study the effective properties of reinforced composites. Classical studies include: the effective conductivity of strongly heterogeneous composites [23], effect of bounds and size in composites with highly conducting interface 
[24], etc. According to micromechanics-based approaches, the effective thermal conductivity of the composites with multiple inhomogeneities (inclusions) can be expressed in terms of the Eshelby tensor and the localization tensor [25,26]. However, these methods hold for a relatively low volume fraction $(<20 \%)$ of fillers. Recently, Lee et. al. have derived an analytical expression for the effective thermal conductivity of composites structured by spherical inclusions and orthotropic matrices by accounting for the effect of interfacial thermal resistance. Their model was based on mean-field approach called the Mori-Tanaka method and validated using Finite Element Methods (FEM) calculations [27]. Models belonging to the class of effective medium approximations (EMA) can also be found in the literature. Among these models, the Bruggeman scheme is considered the most accurate for high filler volume fractions. Based on Bruggeman's symmetric effective-medium formula, a model has been developed to describe the electrical and thermal conductivities of $\mathrm{VO}_{2}$ as well as its specific heat capacity [28].

In our study, we have combined the analytical models based on the Bruggeman scheme and the accuracy of the finite elements methods to predict the effective thermal conductivity of composites based on $\mathrm{VO}_{2}$ and $\mathrm{SiO}_{2}$ as well as its heat storage capacity. We employed a MATLAB ${ }^{\mathrm{TM}}$ code to generate the coordinates of the particles while the function that describes the heat capacity of $\mathrm{VO}_{2}$ was developed in a $\mathrm{C}++$ code. We performed finite element calculations in the modern COMSOL ${ }^{\mathrm{TM}}$ software package for different filler concentration, particle size, and interfacial thermal resistance values. We performed simulations for two systems, first we analyzed a composite structured by $\mathrm{VO}_{2}$ spherical particles embedded into a $\mathrm{SiO}_{2}$ (fused quartz) matrix. Secondly, the inverse system was considered, i.e. $\mathrm{SiO}_{2}$ particles embedded into a $\mathrm{VO}_{2}$ matrix. The simulations were performed using a three-dimensional model considering a cubic matrix. The aim of this study is to determine the influence of the particle size radius $(r)$, interfacial thermal resistance $(R)$ and volume fraction $(f)$ on the effective thermal conductivity (ETC). We compared our calculations with the predictions obtained with the Mori-Tanaka model. Besides, we performed calculations of transition enthalpy, $\Delta H$ for $\mathrm{VO}_{2}$-dispersed glass composites to stablish the optimal parameters that leads to composites with heat storage capacity and the largest thermal conductivity values.

\section{Numerical method}

\subsection{Effective thermal conductivity}

In this section, a methodology for modeling the effective thermal conductivity of particulate composite materials by means numerical calculations is presented. This approach is based on the FEM analysis of a 3D geometry model that consists of a set of spherical particles randomly distributed in a cubic matrix. A MATLAB ${ }^{\mathrm{TM}}$ code generates the position of the inclusions and guarantees that the fillers do not overlap by judging whether the newly generated particle intersects the fillers that have previously been created (see the description of the code in Figure 1). If there is no intersection, it means that the newly generated filler satisfies the condition and is accepted, and on the contrary, is rejected.

The model for the thermal conductivity for $\mathrm{VO}_{2}, \mathrm{kVO}_{2}(\mathrm{~T})$ can be reasonably well described as follows [3], 


$$
k_{V O_{2}}(T)=k_{d}+\frac{k_{m}-k_{d}}{1+e^{-\beta\left(T-T_{c}\right)}}
$$

where $k d=3.6 \mathrm{Wm}^{-1} \mathrm{~K}^{-1}$ and $k m=6.0 \mathrm{Wm}^{-1} \mathrm{~K}^{-1}$ are the thermal conductivity in its dielectric (low temperature) and metallic (high temperature) phases, respectively; $\mathrm{Tc}=342.5 \mathrm{~K}$ is the transition temperature and $\beta=1.6 \mathrm{~K}^{-1}$ is the phase-transition slope of $\mathrm{kVO}_{2}(\mathrm{~T})$ at $\mathrm{T}=\mathrm{Tc}$. These parameters can be obtained fitting the experimental data for $\mathrm{VO}_{2}$ [29] using Eq. (1).

Figure 1 shows the thermal conductivity curves for the materials used in this work. The red curve corresponds to $\mathrm{SiO}_{2}$ (fused quartz), for this type of amorphous solids and for crystalline semiconductors, lattice vibrations are the carriers of heat currents. Theoretically, thermal conduction in bulk amorphous solids is adequately treated by a simple model [30]. For the case of $\mathrm{SiO}_{2}$, the graphical function shows that the conductivity gradually increases with $\mathrm{T}$. For $\mathrm{VO}_{2}$ (black curve) is observed the transition from insulating to metallic phase that occurs at Tc. This function is consistent with data reported for thermal conductivity measurements of $\mathrm{VO}_{2}$ thin films [29].

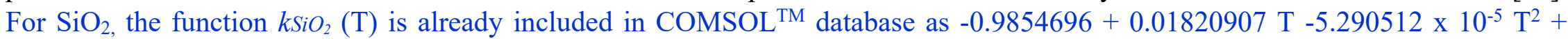
$7.552525 \times 10^{-8} \mathrm{~T}^{3}-5.008123 \times 10^{-11} \mathrm{~T}^{4}+1.311324 \times 10^{-14} \mathrm{~T}^{5}$ for the range $280 \mathrm{~K} \leq \mathrm{T} \leq 1400 \mathrm{~K}$. 

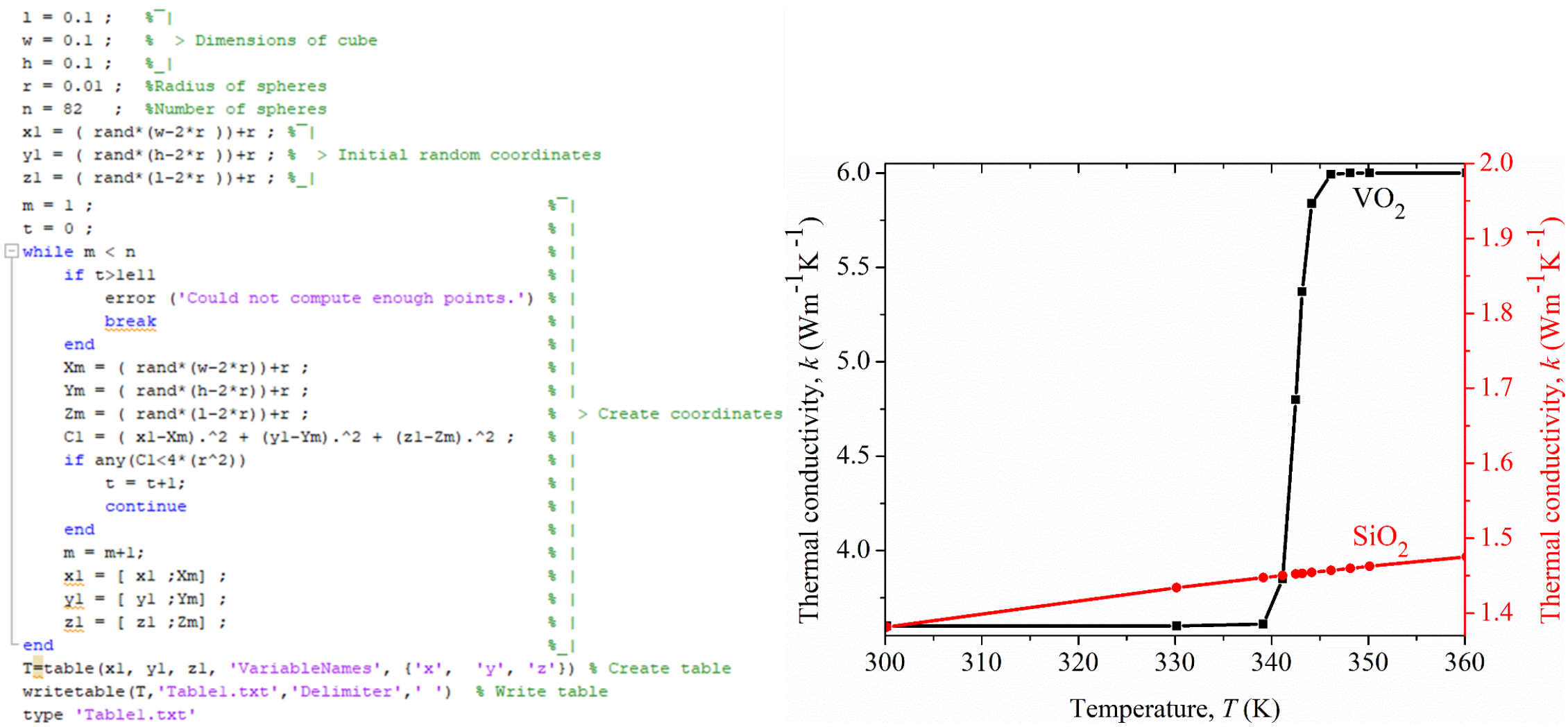

Figure 1. MATLAB ${ }^{\mathrm{TM}}$ code used to generate non-overlapping spherical particles (left). Thermal conductivity curves as a function of temperature for $\mathrm{VO}_{2}$ (black) and $\mathrm{SiO}_{2}$ (red). These curves were obtained from Eq. (1) for $\mathrm{VO}_{2}$ and from $\mathrm{COMSOL}^{\mathrm{TM}}$ database for $\mathrm{SiO}_{2}$ (right).

Figure 2 shows a schematic representation of the used 3D model. The inclusions are randomly distributed in the cubic matrix where $x$ $=z=0$ and $x=z=l$ correspond to adiabatic surfaces. The left surface temperature (red zone) is kept higher than the right one (white zone) in order to induce a heat flux from left to right direction. All the remaining four surfaces are thermally insulated. Density and specific heat are not needed for thermal conductivity calculations as the problem is steady state. The average value of conductive heat flux normal to all three xz surfaces is used to calculate the keff using the Fourier law of heat conduction in the cubic system,

$$
\nabla \cdot\left(k_{e f f} T\right)=0 .
$$


For heat flow in the $\mathrm{x}$ direction, the following expression is used,

$$
k_{e f f}=\frac{q l}{A\left(T_{\text {hot }}-T_{\text {cold }}\right)},
$$

where $q$ is the heat flux through the cubic cell calculated by integration on the temperature face imposed as $T_{\text {cold, }}$, as follows,

$$
q=\iint q_{x}(x, y, z) d y d z
$$

keff is the effective thermal conductivity of the composite, $A$ is the cross-sectional area of the computational domain perpendicular to the $x$-axis. Notice that $A=l^{2}$, then simplifying we can obtain the expression,

$$
k_{e f f}=\frac{q}{l\left(T_{\text {hot }}-T_{\text {cold }}\right)}
$$



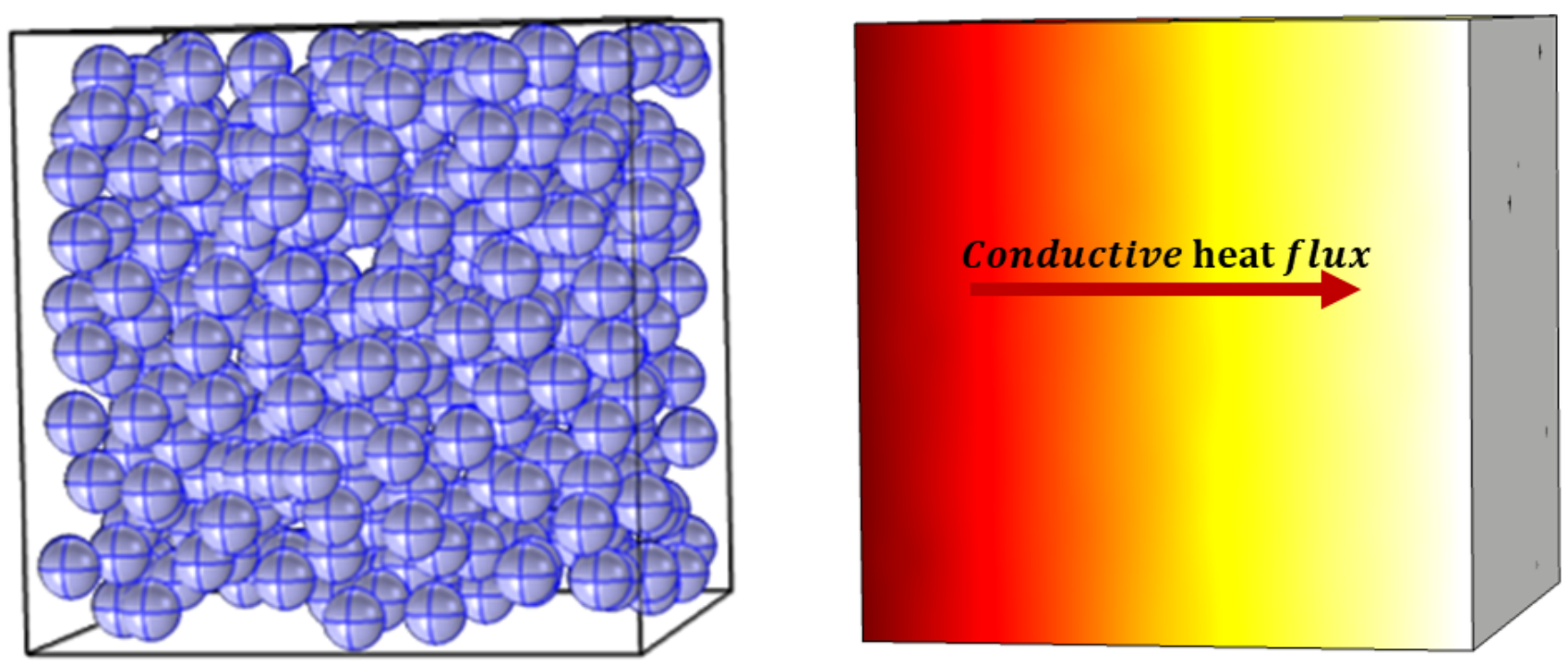

Figure 2. Diagram for the representation of the 3D composite model.

The described approach does not consider the effects associated with the interface thermal resistance. In order to obtain more realistic results, we now turn our attention to the system where the imperfect thermal contact between two adjacent materials of a composite is considered [31]. This interface is considered as a thin interface layer between the phases where heat cannot flow directly through the layer which results in a temperature jump across the interface. The interfacial thermal resistance, $R$ is defined as

$$
T^{\text {out }}-T^{\text {in }}=-R q_{s} \cdot n \text {, }
$$

where $\mathrm{T}^{\text {out }}$ and $\mathrm{T}^{\mathrm{in}}$ refer to temperatures at the outer and inner surfaces of the interface, respectively, $q_{s}$ is the heat flux at the interface, and the $n$ is the outward surface normal vector.

For the calculations, COMSOL ${ }^{\mathrm{TM}}$ introduces the boundary condition of the thin thermal resistive layer to the interior boundaries between the particles and matrix by means a method model that we have developed on the Application Builder window. The calculated thermal conductivity of the sample from Eq. (5) is the thermal conductivity at the average temperature thereof. 


\subsection{Validation against Mori-Tanaka model}

As has been mentioned before, Lee et. al. derived a closed form solution for the effective thermal conductivity based on the MoriTanaka method. This analytical function can be applied to composites with isotropic fillers and orthotropic or transversely isotropic matrices. In our study we employed $\mathrm{SiO}_{2}$ fused quartz (amorphous) that belongs to the group of isotropic materials [32,33]. Therefore, we can compare our results to the effective thermal conductivity of the $3 \mathrm{D}$ Mori-Tanaka model, $k^{M T}$, for isotropic matrices according to the equation,

$$
k^{M T}=k_{\text {matrix }}\left\{1+\frac{3 f\left(k_{\text {matrix }}-k_{\text {fillers }}+\frac{k_{\text {matrix }} k_{\text {fillers }} R}{r}\right)}{3 f k_{\text {fillers }}+(1-f)\left[2 k_{\text {matrix }}\left(1+\frac{R k_{\text {fillers }}}{r}\right)+k_{\text {fillers }}\right]}\right\}^{-1} .
$$

Note that the thermal conductivity of matrix and fillers, kmatrix and kfillers, respectively, are temperature dependent functions.

\subsection{Determination of heat storage capacity}

At constant pressure, the heat capacity for a material is expressed as follows,

$$
C p=\left(\frac{\partial H}{\partial T}\right)_{P}
$$

separating variables, we can integrate the area inside the peak of the curve $C p$ vs $\mathrm{T}$ to obtain the thermodynamic variable known as transition enthalpy, $\Delta H=\int C p \mathrm{dT}$, that corresponds to the amount of the stored latent heat. As it is well known, the heat capacity is an extensive property of the matter, thus according to the rule of mixtures the effective heat capacity, Cpeff, for composite 1 can be written as follows, 


$$
C p_{e f f}=x_{\mathrm{VO}_{2}} C p_{\mathrm{VO}_{2}}(T)+x_{\mathrm{SiO}_{2}} C p_{\mathrm{SiO}_{2}}(T),
$$

where $x_{\mathrm{VO} 2}$ and $x_{\mathrm{SiO} 2}$ are the mass of $\mathrm{VO}_{2}$ and $\mathrm{SiO}_{2}$ respectively and $\mathrm{CpNO}_{2}$ and $\mathrm{CpSiO}_{2}$ are the heat capacity functions of $\mathrm{VO}_{2}$ and $\mathrm{SiO}_{2}$, respectively. For $\mathrm{SiO}_{2}$, the function is already included in $\mathrm{COMSOL}^{\mathrm{TM}}$ database as $61.49405+1.926794 \mathrm{~T}+0.004463629 \mathrm{~T}^{2}-$ $1.704271 \times 10^{-5} \mathrm{~T}^{3}+1.88109 \times 10^{-8} \mathrm{~T}^{4}-7.062466 \times 10^{-12} \mathrm{~T}^{5}$ for the range $115 \mathrm{~K} \leq \mathrm{T} \leq 925 \mathrm{~K}$. Meanwhile Ordonez et. al. developed a model to describe the temperature evolution of the specific heat capacity of $\mathrm{VO}_{2}$ at constant pressure. For the heating process, the specific heat capacity of $\mathrm{VO}_{2}$ at temperature $\mathrm{T}$ can be written as follows [28].

$$
C p_{V O_{2}}(T)=C_{D}(T)+L_{l} \frac{d k_{V O 2}}{d T},
$$

where $C_{D}(\mathrm{~T})$ is the specific heat capacity predicted by the Debye model, $\rho$ is the density, and $L l$ is the heat latent of $\mathrm{VO}_{2}$. From Eq. (3) we obtain,

$$
C p_{V O_{2}}(T)=C_{D}(T)+L_{l} \frac{\left(k_{m}-k_{d}\right) \beta e^{-\beta\left(T-T_{c}\right)}}{\left[1+e^{-\beta\left(T-T_{c}\right)}\right]^{2}} .
$$

The function that describes the Debye model was developed in a $\mathrm{C}++$ code and called externally from $\mathrm{COMSOL}^{\mathrm{TM}}$ as Debye(T) (see flowchart depicted in Figure. S1 in Supplementary Material).

\subsection{Validation of the method against experimental data}

In addition to the validation of our results with the Mori-Tanaka model, in this section we present the validation of our numerical method against experimental data. Although not many experimental studies on the effective thermal conductivity of $\mathrm{VO}_{2}$-based composites are reported in the literature, we have been able to compare our numerical approach with the work reported in [12]. We have simulated the paraffin@ $\mathrm{VO}_{2} \mathrm{PCM}$ by means a 2D particulate composite made up of paraffin wax particles embedded into a $\mathrm{VO}_{2}$ matrix (see Figure 14(a)). For this system, Ti has been used to dop $\mathrm{VO}_{2}$ and reduce its transition temperature. Generally, dopants with high-valent transition metals decrease the transition temperature [34]. 
Thus, we have adapted the new value of transition temperature $(\mathrm{Tc}=331.55 \mathrm{~K})$ and we supposed a value of $\mathrm{km}^{2}=5.4 \mathrm{Wm}^{-1} \mathrm{~K}^{-1}$ for the thermal conductivity in $\mathrm{VO}_{2}$ metallic phase. As in the original paper, we performed calculations for two paraffin@ $\mathrm{VO}_{2} \mathrm{PCM}_{\mathrm{samples}}$ with $\mathrm{VO}_{2}$ mass ratio of 4.5 and 8.2. Mathematically we can express the first ratio as $m_{\mathrm{VO}_{2}} / m_{\text {paraffin }}=4.5$. Now converting this ratio into volume percentage, we obtain

$$
f=\frac{450 \rho_{\text {paraffin }}}{4.5 \rho_{\text {paraffin }}+\rho_{V O 2}} .
$$

A similar equation can be obtained for the second sample. Therefore, from the density values detailed in Table 1 , the mass ratios of 4.5 and 8.2 are equivalent to 42.8 and 57.7 volume percentage or 0.75 and 1.36 volume proportion of $\mathrm{VO}_{2}$.

Table 1. Thermal properties for the components of the paraffin@ $\mathrm{VO}_{2} \mathrm{PCM}$.

\begin{tabular}{cccc}
\hline Density $\left(\mathrm{kg} \mathrm{m}^{-3}\right)$ & $\begin{array}{c}\text { Thermal } \\
\text { conductivity } \\
\left(\mathrm{Wm}^{-1} \mathrm{~K}^{-1}\right)\end{array}$ & $\begin{array}{c}\text { Average particle } \\
\text { diameter }(\mu \mathrm{m})\end{array}$ \\
\hline $\mathrm{VO}_{2}$ & 4670 & $3.6-5.4$ & 10 \\
Wax paraffin & 778 & 0.2 & 10 \\
\hline
\end{tabular}

\section{Results and discussions}

\section{1. $\mathrm{VO}_{2}$ particles embedded in a $\mathrm{SiO}_{2}$ matrix}

We define the system structured with $\mathrm{VO}_{2}$ particles embedded in a $\mathrm{SiO}_{2}$ matrix as Composite 1. First, we discuss the results without considering the thermal resistance effect. The simulations were performed for different particle size with sphere radius $(r): r 1=1 \mu \mathrm{m}$; $r 2=10 \mu \mathrm{m} ; r 3=95 \mu \mathrm{m}$ and temperature values from $300 \mathrm{~K}$ to $360 \mathrm{~K}$. In all cases, volume fraction of $0.043,0.140,0.170,0.251$, 0.341 and 0.402 of $\mathrm{VO}_{2}$ were considered. It is important to note that for all calculations we have fixed a small temperature difference 
$(\sim 5 \mathrm{~K})$, this consideration allows us to reproduce data, which are consistent with the reported experimental data for $\mathrm{VO}_{2}$ in Figure 1 . A similar procedure has been employed to calculate the thermoelectric properties for a particulate composite in which the temperature difference between the hot and the cold side was fixed at $1 \%$ of the average temperature (300 K) [35]. The average values of ETC without considering the effect of the interfacial thermal resistance are shown in Figures 3(a) and 3(b). Clearly, we can note that at constant temperature, higher volume fractions, results in higher the thermal conductivities. When the temperature difference is large, not all sections of the sample reach the desired temperature $(342.5 \mathrm{~K}$ for this example) for the calculation of the effective conductivity.
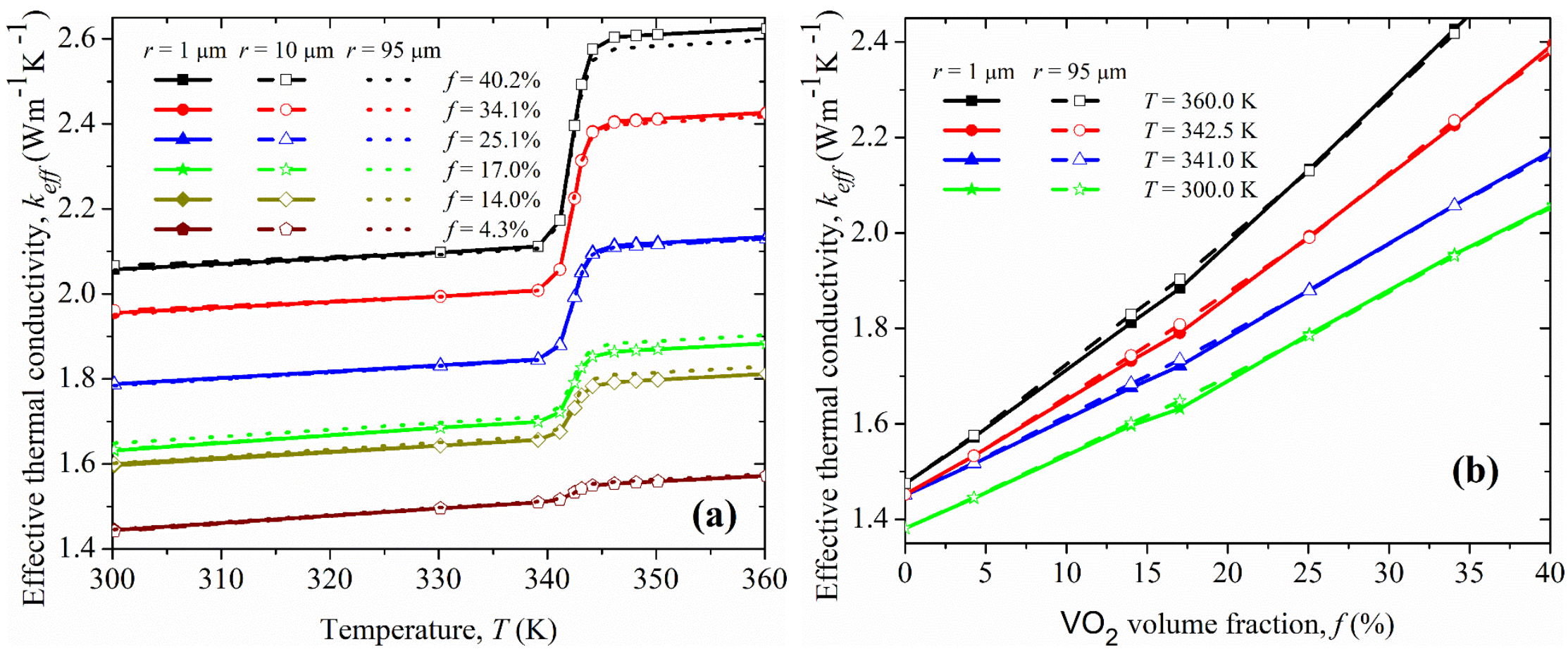

Figure 3. Comparison of the particle size effect on effective thermal conductivity as a function of (a) Temperature and, (b) $\mathrm{VO}_{2}$ volume fraction of the particles. Calculations were performed at different $\mathrm{VO}_{2}$ volume fractions for (a) and different temperatures for (b). For the figure on the right, the curves for $r=10 \mu \mathrm{m}$ and $r=95 \mu \mathrm{m}$ are very similar.

The lower the volume fraction of $\mathrm{VO}_{2}$ and the larger the particle size, the higher the ETC values. However, as the volume fraction of $\mathrm{VO}_{2}$ increases, the lower particle radius $(r=1 \mu \mathrm{m})$ is slightly predominant due to small particles trend to form conductive chains (see Figure 4(a)) causing a large increase in total heat flux that increase the effective thermal conductivity. The addition of $\mathrm{VO}_{2}$ into the 
$\mathrm{SiO}_{2}$ matrix increases the total thermal conductivity in both insulating and conducting phases, although the $\mathrm{VO}_{2}$ particle size does not play an important role for the effective thermal conductivity for composite 1.

The results of numerical calculation versus filler volume fraction are shown in Figure 4(b). The average values of the effective thermal conductivity increase as volumetric fraction of $\mathrm{VO}_{2}$ increases. Note that $0 \%$ volume fraction represents pure $\mathrm{SiO}_{2}$. In the simulation results, the effect of interface thermal resistance has not been considered as mentioned before. Then, these results could be useful if the particles are relatively large (guaranteeing minimal interfacial area) so that such effect can be neglected.
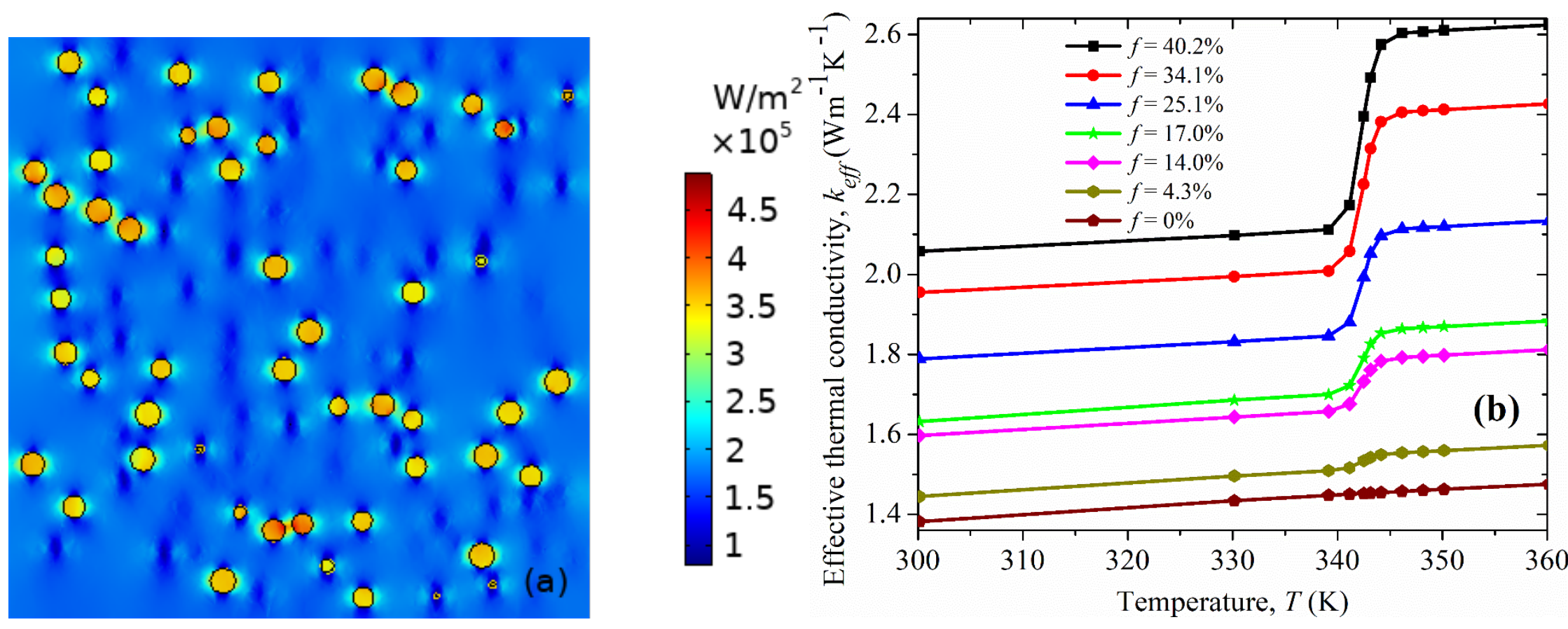

Figure 4. a) Cut plane of the 3D thermal flux profile (side view) considering $r=1 \mu \mathrm{m}$. b) Results of calculations performed in $\mathrm{COMSOL}^{\mathrm{TM}}$ for the effective thermal conductivity of composite 1 . Calculations were performed for different volume fractions of $\mathrm{VO}_{2}$ and $r=1 \mu \mathrm{m}$.

It has been found that in structured composites with high filler loading, interfacial thermal resistance has a significant effect [36]. Therefore, this effect is also included in this study. To better understand the effect of interfacial thermal resistance, we show the cut planes of the $3 \mathrm{D}$ model for the temperature contours along the direction of heat flow through the $\mathrm{VO}_{2}$ particles dispersed in the $\mathrm{SiO} 2$ 
matrix. Figure 5(a) illustrates a thermal profile without considering the effect of interfacial thermal resistance, while the profile in figure 5(b) does. Thermal profile for large values of ITR is shown in figure 5(b), the yellow arrows indicating the temperature jumps across the interface along the boundary of the $\mathrm{VO}_{2}$ particles. Note that in this case the $\mathrm{VO}_{2}$ particles are in the metallic phase.
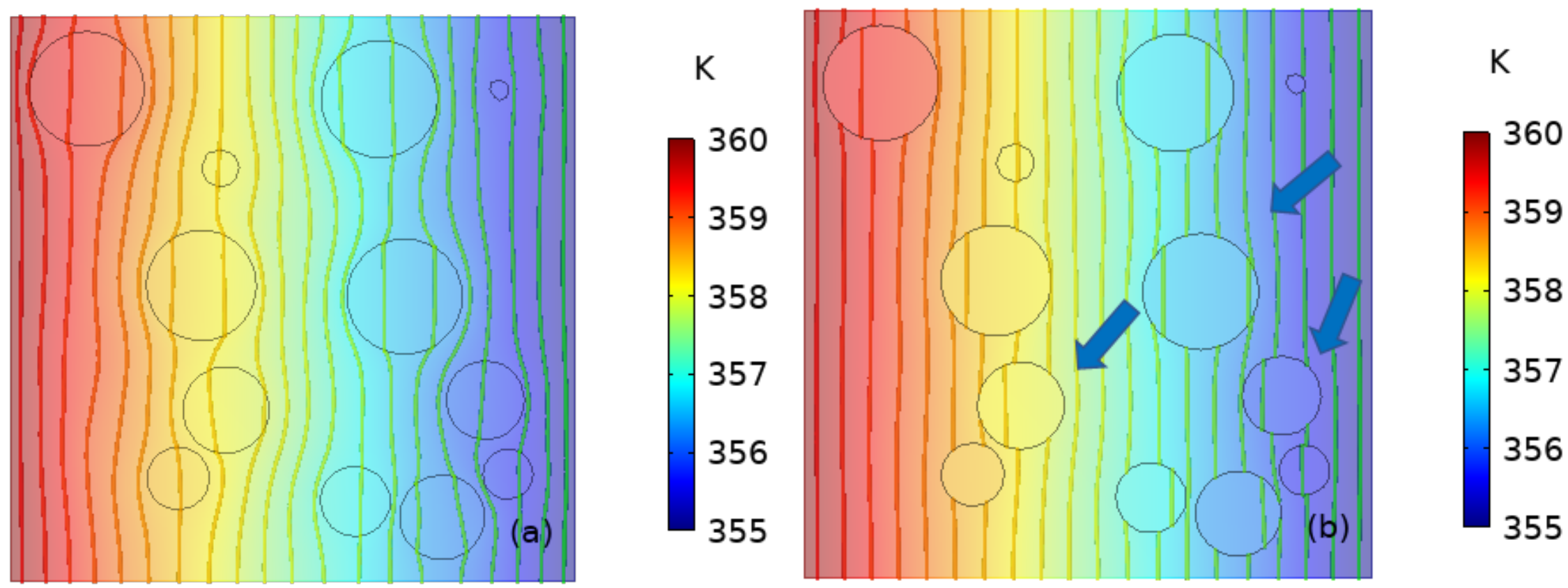

Figure 5. Comparison of the interfacial thermal resistance effect on the cut planes of the 3D temperature contours (side view) for composite 1. Calculations were performed considering $R=0 \mathrm{~m}^{2} \mathrm{KGW}^{-1}$ for (a) and the largest value of $R$ in this study $(R=100$ $\left.\mathrm{m}^{2} \mathrm{KGW}^{-1}\right)$ for $(\mathrm{b})$.

Besides, in this work we analyze how the interfacial resistance affects the ETC at different values of particle size. In figures 6(a) we illustrate the ETC values as a function of ITR at different particle sizes. As we can see, the effective thermal conductivity is strongly affected when $r=1 \mu \mathrm{m}$ as the volumetric fraction increases. Note that the ETC values for $r=10 \mu \mathrm{m}$ and $r=95 \mu \mathrm{m}$ are similar, so we proceed to analyze the influence of the resistance on the ETC considering $r=1 \mu \mathrm{m}$ and $r=10 \mu \mathrm{m}$. Figure 6(b) displays the ETC values as a function of temperature for different thermal resistance values. Note that the distance between the set of curves with $r=10$ $\mu \mathrm{m}$ and the set of curves with $r=1 \mu \mathrm{m}$ is larger in the temperature range $\mathrm{T}>\mathrm{Tc}\left(\mathrm{VO}_{2}\right.$ transition temperature). This fact indicates that the effect of thermal resistance is stronger when $\mathrm{VO}_{2}$ is in the metallic phase. For more details see Figure S2 in the Supplementary 
Material. For this system, as the particle size tends to the micro- or nanoscale, thermal transport across interfaces dominates the heat transport in the whole system. If we consider that before the transition temperature heat conduction is due to phonons while after the transition temperature heat conduction is due to phonons and electrons, then electrons due to $\mathrm{VO}_{2}$ (in metallic phase) and phonons due to $\mathrm{SiO}_{2}$ (insulator) yield electron-phonon coupling at interfaces where thermal resistance becomes stronger. This effect was also observed in a metal-semiconductor periodic multilayered system [37].
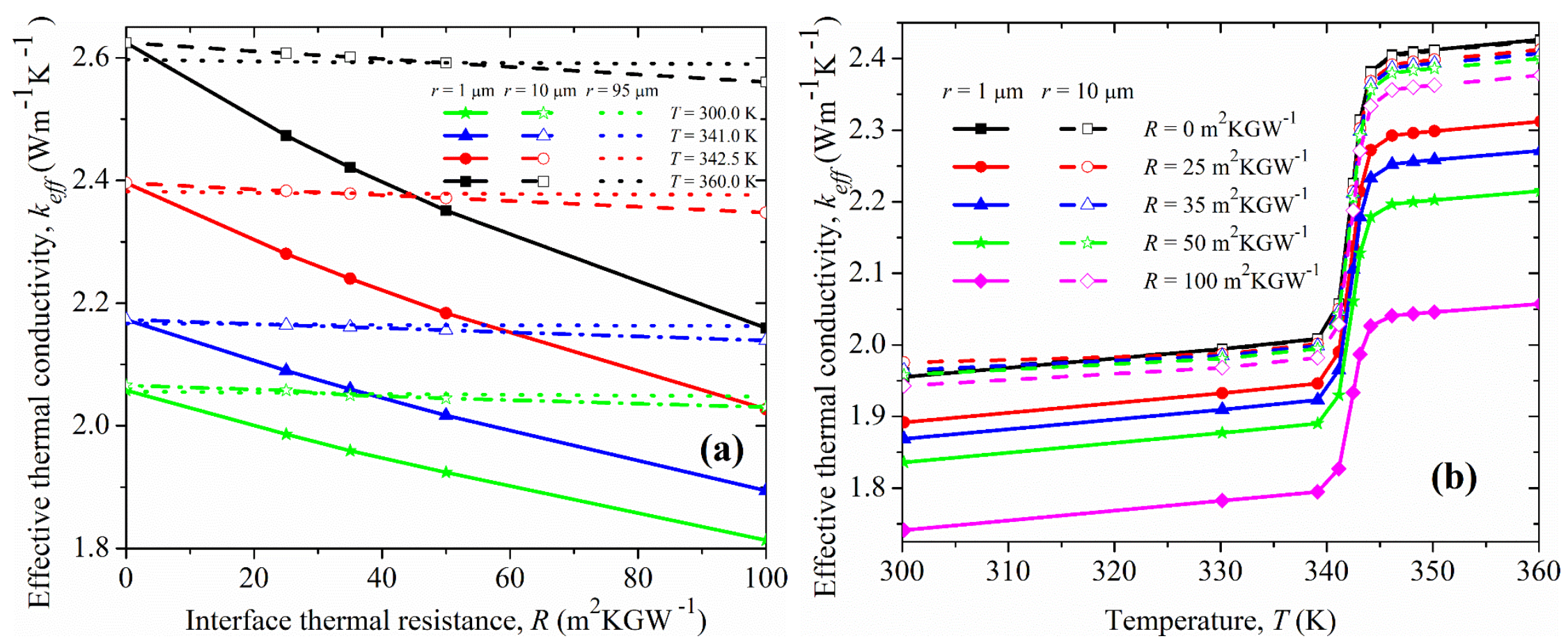

Figure 6. Comparison of the effect of particle size on effective thermal conductivity as a function of (a) interfacial thermal resistance, and (b) temperature. Calculations were performed at different temperatures and considering $f=40.2 \%$ of $\mathrm{VO}_{2}$ for (a) and different interfacial thermal resistance values with $f=34.1 \%$ of $\mathrm{VO}_{2}$ for (b).

In Figure 7 we illustrate the values of ETC at $f: 4.3,17.0$ and $40.2 \%$ of $\mathrm{VO}_{2}$ for $r=1 \mu \mathrm{m}$. As the volume fraction increases, the ETC decreases. This means that the effective thermal conductivity is highly dependent on particle size and volume fraction if interfacial thermal resistance is present. In the same way, the size of $\mathrm{Al}_{2} \mathrm{O}_{3}$ particles has a strong effect on the thermal conductivity of the silicone rubber composites [38]. 


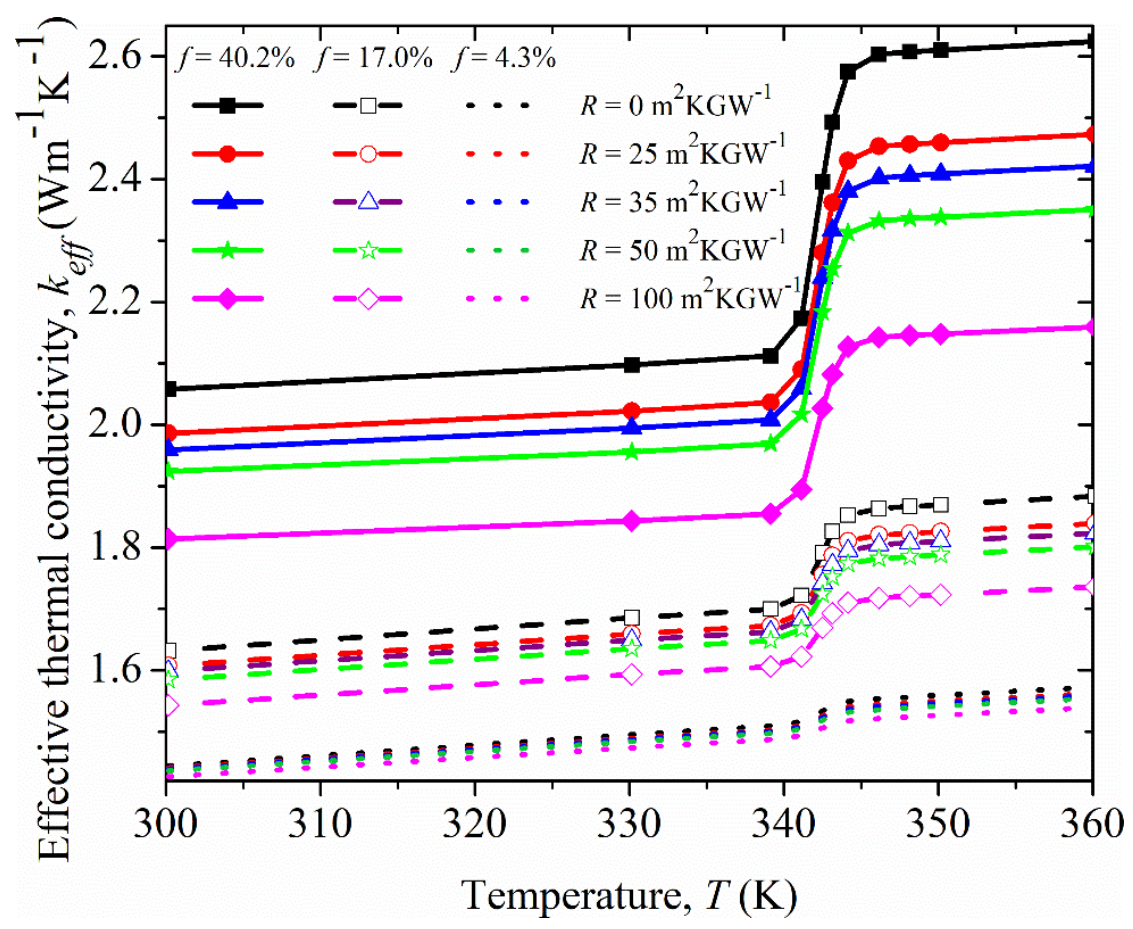

Figure 7. Effect of interfacial thermal resistance when the volumetric fraction of $\mathrm{VO}_{2}$ varies. Calculations were performed considering $r=1 \mu \mathrm{m}$.

The value of the interfacial thermal resistance between $\mathrm{VO}_{2}$ and $\mathrm{SiO}_{2}$ has not been directly measured. However, we have considered a value of $\sim 35 \mathrm{~m}^{2} \mathrm{KGW}^{-1}$ based on the measurement of Hamaoui et. al. [39] for the interface thermal resistance between $\mathrm{VO}_{2}$ and $\mathrm{Si}$. It is assumed here that the interfacial thermal resistance between $\mathrm{VO}_{2}$ and glass-like materials (i.e., silicone, $\mathrm{SiO}$, etc.) does not differ significantly.

Then we perform calculations for this thermal resistance value. Figure 8(a) shows that the effective thermal conductivity with the larger $\mathrm{VO}_{2}$ particle size is higher than that of a small particle size under the same volume fraction. The same phenomenon can be found in silicone/phosphor composites [40]. The increase is due to the larger the $\mathrm{VO}_{2}$ particle, the lower the specific surface area it is, which leads to less scattering phenomenon in thermal barrier. When the particle size decreases, the particles cannot be able to contact well with each other, and the thermal contact resistance dominates the heat transfer process. 
We compared our calculations and the corresponding Mori-Tanaka approach for $r=1 \mu \mathrm{m}$ (see Figure $8 \mathrm{~b}$ ). As we can see, both approaches predict the same trend for the effective thermal conductivity. That is consistent with the results reported by Lee et. al. where the analytical predictions are in good agreement with the FEM results obtained from COMSOL ${ }^{\mathrm{TM}}$ [27]. The plot correspondingly to the heat flux profile for composite 1 when $R=35 \mathrm{~m}^{2} \mathrm{KGW}^{-1}$ and $r=1 \mu \mathrm{m}$ is shown in Figure $\mathrm{S} 3$ (see Supplementary Material). Note that for $R=0 \mathrm{~m}^{2} \mathrm{KGW}^{-1}$ the profile looks less "bright" (see Figure 4(a)) than for $R=35 \mathrm{~m}^{2} \mathrm{KGW}^{-1}$. Besides, when $\mathrm{R}=35 \mathrm{~m}^{2} \mathrm{KGW}^{-1}$ the heat flow is less than when $\mathrm{R}=0 \mathrm{~m}^{2} \mathrm{KGW}^{-1}$, as expected.
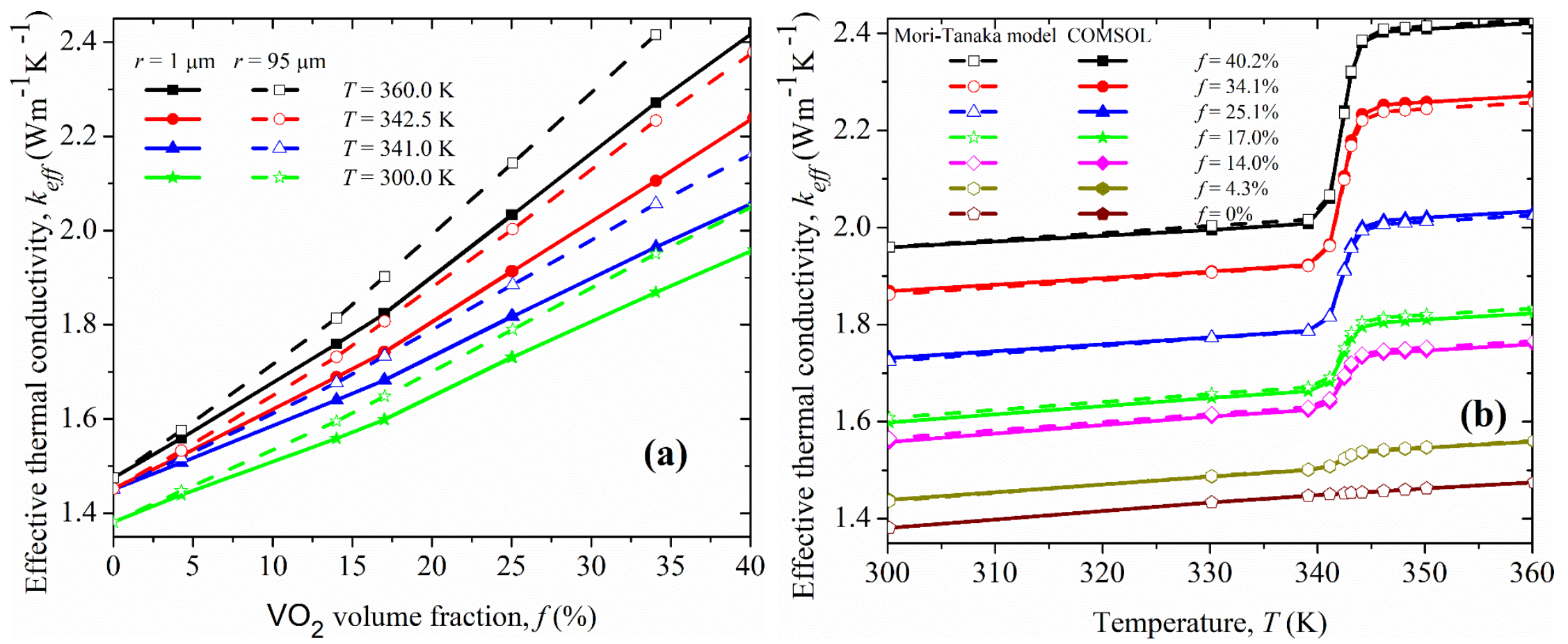

Figure 8. (a) Comparison of the particle size effect on effective thermal conductivity as a function of $\mathrm{VO}_{2}$ volume fraction. Calculations were performed at different temperatures and considering $f=40.2 \%$ of $\mathrm{VO}_{2}$. (b) Comparison between calculations for $R$ $=0 \mathrm{~m}^{2} \mathrm{KGW}^{-1}$ and $R=35 \mathrm{~m}^{2} \mathrm{KGW}^{-1}$ considering $r=1 \mu \mathrm{m}$.

Figure 9(a) portrays the ETC values for the three values of the radius considered in this study. These calculations may be used to determine the optimal particle size for modulate the effective thermal conductivity of this kind of composites. Note that all the analyses were performed for $\mathrm{VO}_{2}$ particles completely embedded in the glass matrix, which would be crucial in real systems 
considering that $\mathrm{SiO}_{2}$ prevents the degradation of $\mathrm{VO}_{2}$, by induced moisture [13]. Figure $9 \mathrm{~b}$ depicts the effective thermal conductivity slope as a function of the temperature for composite 1, as we can see, a composite whose resistance trends to zero will undergoes steeper thermal conductivity slopes. Phase change materials (PCMs) with faster phase transitions can be used to develop diverse thermally operated devices, for example thermal diodes with improved rectification of heat currents [3].
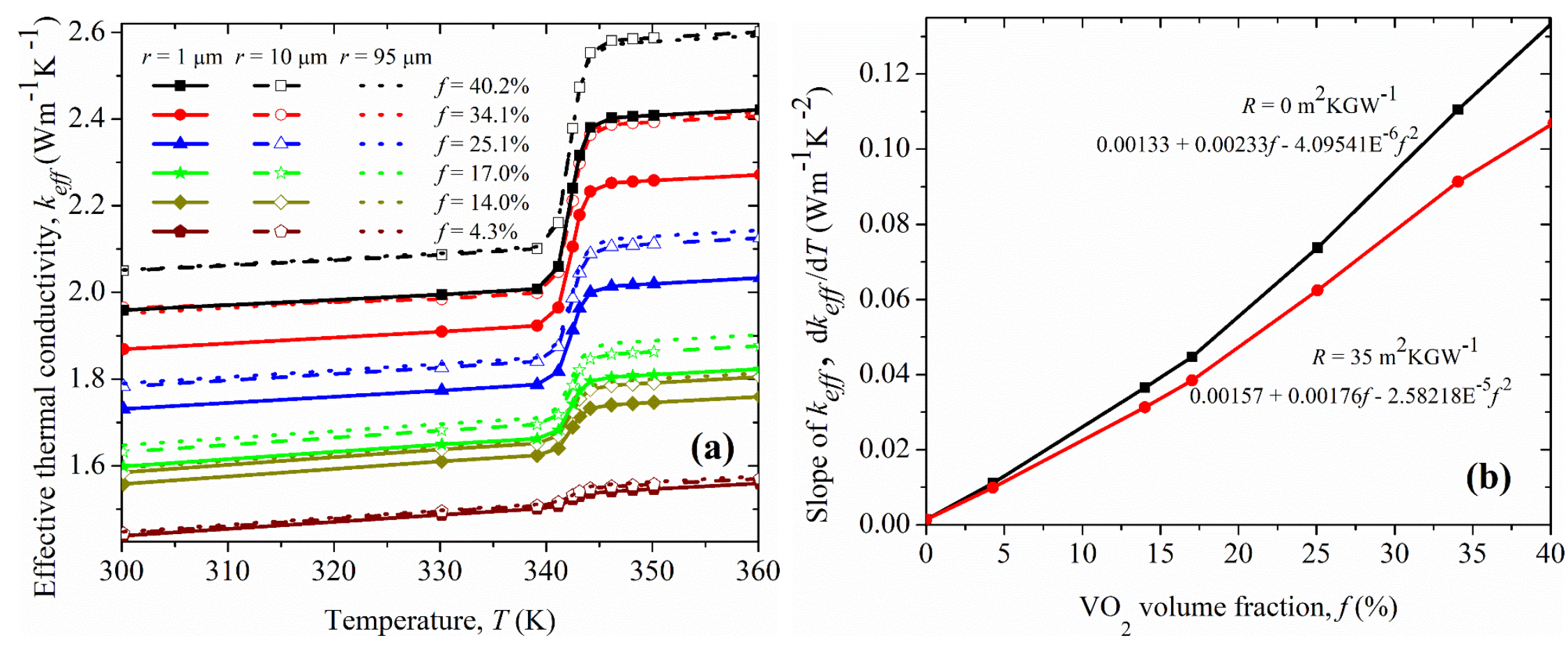

Figure 9. (a) Representation of the particle size and $\mathrm{VO}_{2}$ volumetric fraction effect on effective thermal conductivity as a function of temperature. (b) Comparison of the slopes for effective thermal conductivity for $R=0 \mathrm{~m}^{2} \mathrm{KGW}^{-1}$ (black curve) and $R=35 \mathrm{~m}^{2} \mathrm{KGW}^{-1}$ (red curve). For the figure on the right, the curves were obtained considering $r=1 \mu \mathrm{m}$. An approximation for the slope of red curve indicates that the ETC increases at a rate of $2.7 \times 10^{-3} \mathrm{Wm}^{-1} \mathrm{~K}^{-2}$.

\subsubsection{Heat storage capacity}


As the volumetric fraction of $\mathrm{VO}_{2}$ increases the $\Delta H$ values increase, for the maximum concentration $(f=40.2 \%)$ shown in Figure 10 , the corresponding calculated area yields a $\Delta H$ value of $24553 \mathrm{~J} \mathrm{~kg}^{-1}\left(486.7 \mathrm{cal} \mathrm{mol}^{-1}\right)$ which corresponds to $\sim 48 \%$ of that of the pure $\mathrm{VO}_{2}$ (1007 cal mol${ }^{-1}$, see Supplementary Material, Figure S4).

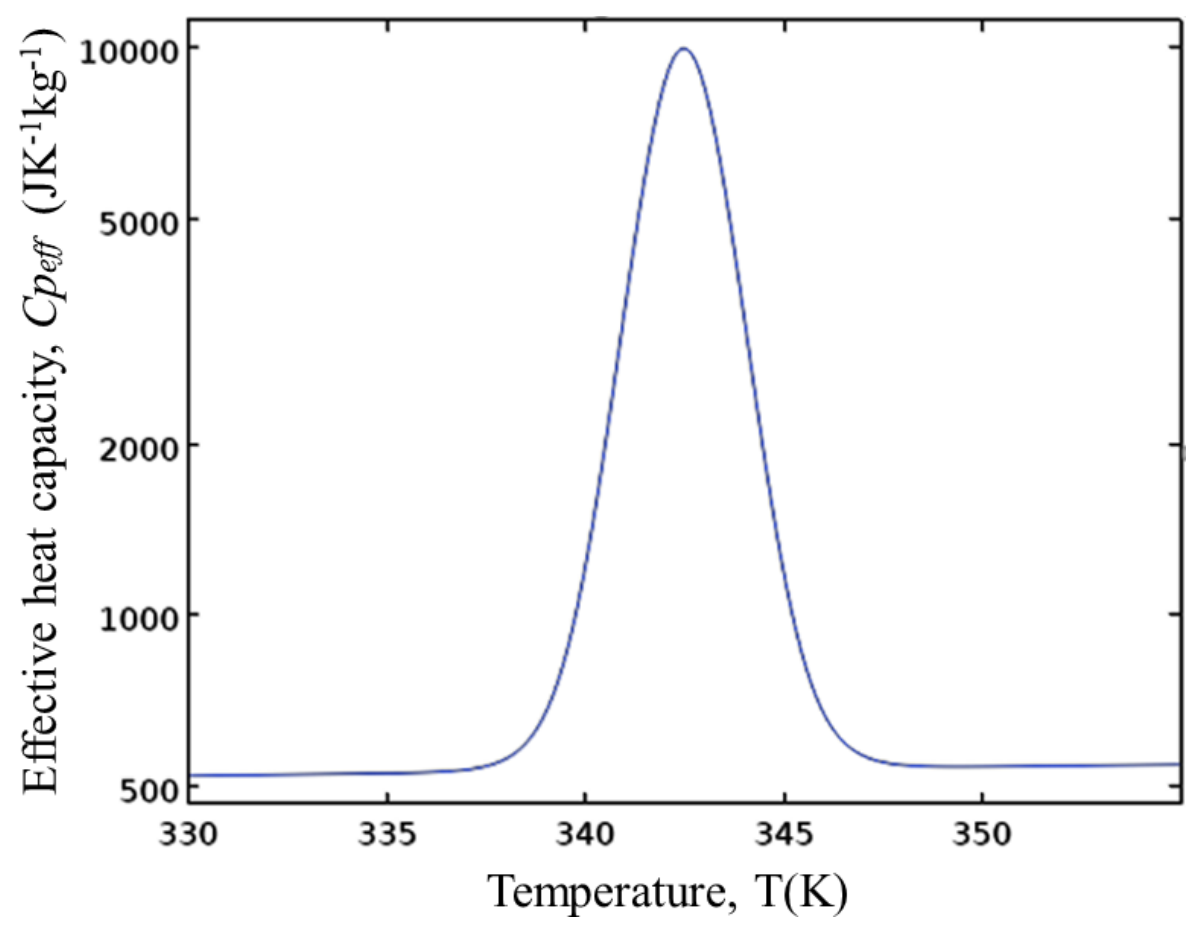

Figure 10. Heat capacity as a function of temperature for composite 1 with $40.2 \% \mathrm{VO}_{2}$ (in volume). The area under the curve corresponds to latent heat storage capacity.

If we take into account these complementary calculations, we can adjust or modulate the effective thermal conductivity according to the desired requirements. As we can see in Table 2, for a same value of latent heat storage capacity we can obtain different values of thermal conductivity depending on the particle size and the existence or not of interfacial thermal resistance.

Table 2 Thermal properties of composite 1. 


\begin{tabular}{ccccc}
\hline $\begin{array}{c}\text { Volumetric fraction of } \\
\mathrm{VO}_{2}(\%)\end{array}$ & Particle size $(\mu \mathrm{m})$ & $\begin{array}{c}\text { Interfacial thermal } \\
\text { resistance }\left(\mathrm{m}^{2} \mathrm{KGW}^{-1}\right)\end{array}$ & $\begin{array}{c}\text { Latent heat storage } \\
\text { capacity }\left(\mathrm{Jkg}^{-1}\right)\end{array}$ & $\begin{array}{c}\text { Effective thermal } \\
\text { conductivity }\left(\mathrm{Wm}^{-1} \mathrm{~K}^{-1}\right)\end{array}$ \\
\hline \multirow{2}{*}{40.2} & 1 & $\sim 0$ & & 2.62 \\
& & 35 & 24553 & 2.42 \\
& \multirow{2}{*}{95} & 35 & & 2.59 \\
& & 35 & 2.59 \\
\hline
\end{tabular}

\section{2. $\mathrm{SiO}_{2}$ particles embedded in a $\mathrm{VO}_{2}$ matrix}

We define the system structured with $\mathrm{SiO}_{2}$ particles embedded in a $\mathrm{VO}_{2}$ matrix as Composite 2. Similarly, we consider the same values of volume fraction and range of temperatures as for composite 1 . The average values of effective thermal conductivity versus temperature and versus filler volume fraction are shown in Figures 11(a) and 11(b), respectively. As shown in both figures, for different $\mathrm{SiO}_{2}$ particle sizes, the corresponding ETC values are practically the same indicating that particle size does not represent an important factor in these systems. 

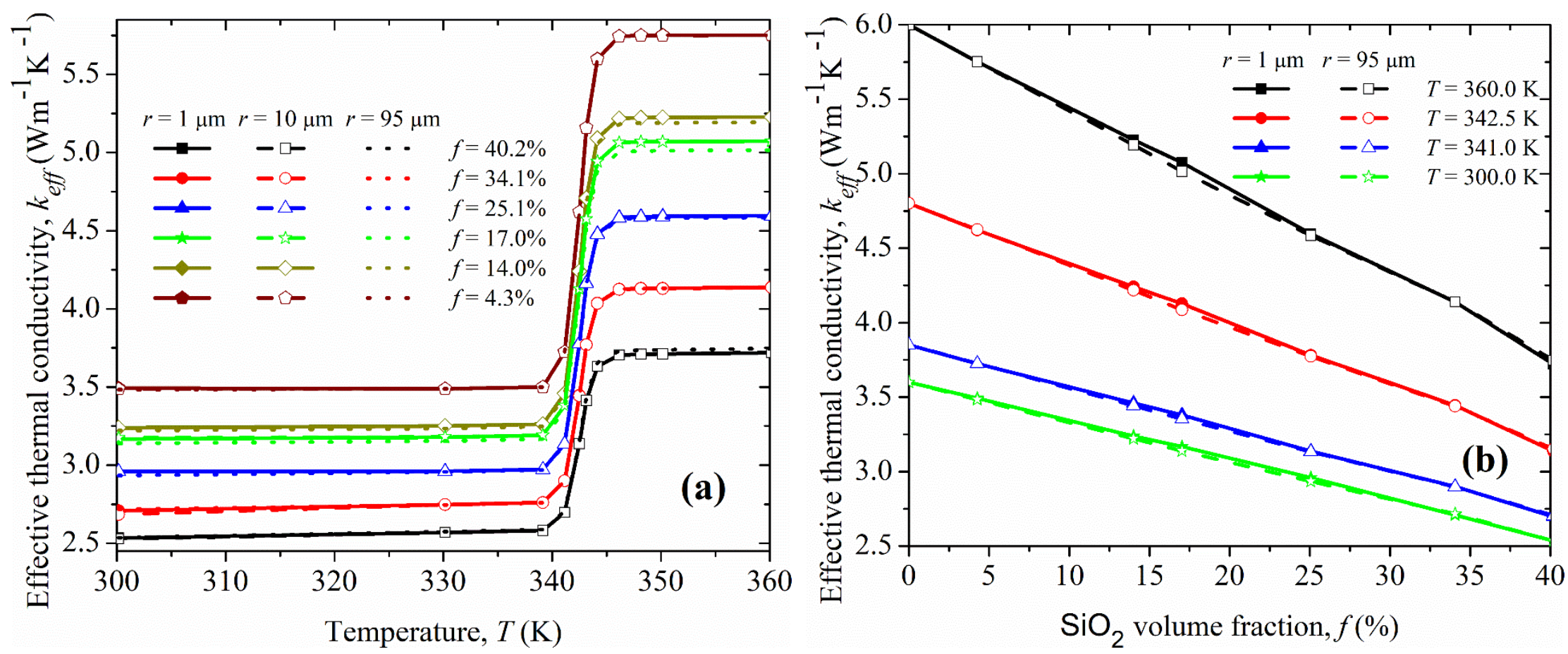

Figure 11. Comparison of the particle size effect on effective thermal conductivity as a function of (a) $\mathrm{Temperature} \mathrm{and,} \mathrm{(b)} \mathrm{SiO}_{2}$ volume fraction. Calculations were performed at different $\mathrm{SiO}_{2}$ volume fractions for (a) and different temperatures for (b). For the figure on the right, the curves for $r=10 \mu \mathrm{m}$ and $r=95 \mu \mathrm{m}$ are very similar.

As in composite 1, we also evaluated the interfacial thermal resistance effect on ETC considering different $\mathrm{SiO}_{2}$ particle sizes. Figure 12(a) shows that the ETC values decrease when ITR increases. However, this decrease is not as large as for composite 1, in this case the interfacial thermal resistance will retard less heat transfer of composites, thus decreasing the thermal conductivity as $\mathrm{SiO}_{2} \mathrm{Volume}$ fraction increases. In contrast to composite 1, when the matrix is $\mathrm{VO}_{2}$ the particle size does not have a significant influence on the effective thermal conductivity as is depicted in Figure 12(b). 

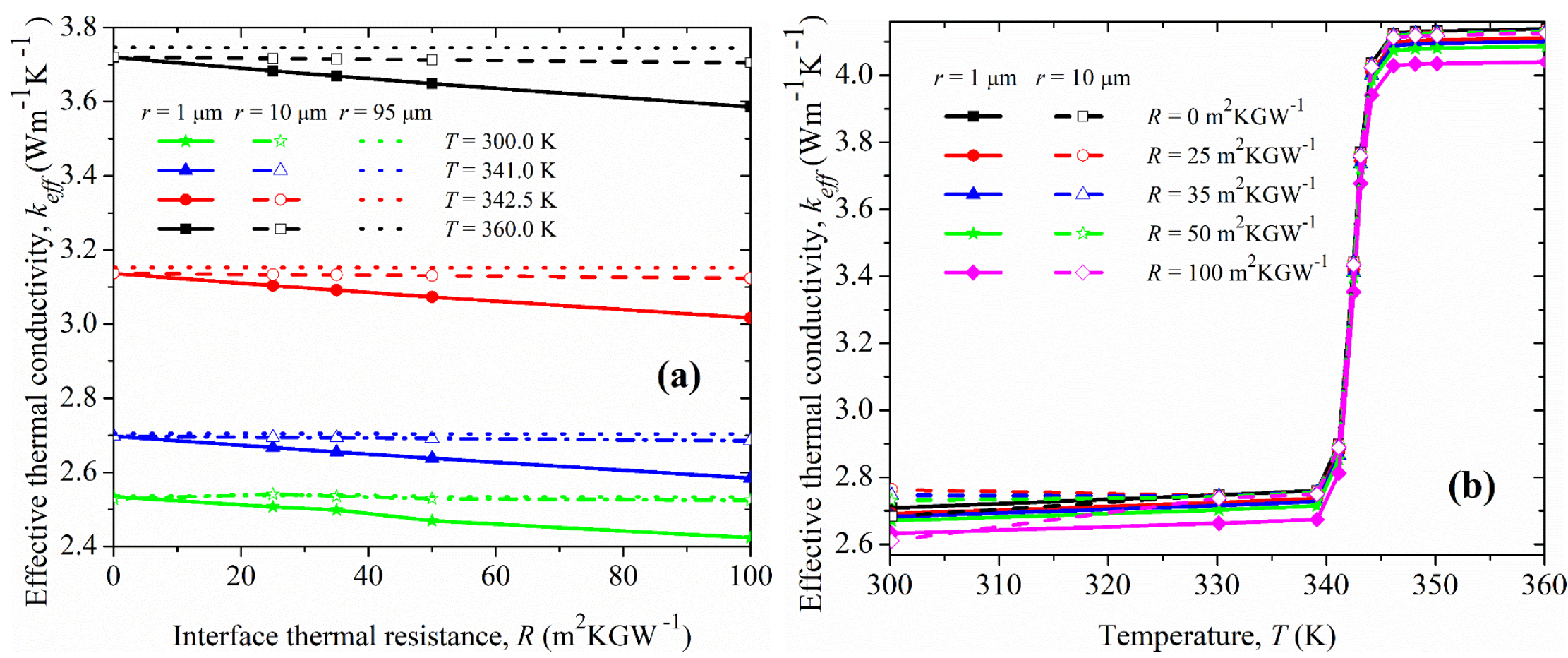

Figure 12. Comparison of the particle size effect on effective thermal conductivity as a function of (a) interfacial thermal resistance, (b) temperature. Calculations were performed at different temperatures and considering $f=40.2 \%$ of $\mathrm{SiO}_{2}$ for (a) and different interfacial thermal resistance values with $f=34.1 \%$ of $\mathrm{SiO}_{2}$ for (b).

Considering a thermal resistance of $R=35 \mathrm{~m}^{2} \mathrm{KGW}^{-1}$, our results can be compared with the ones obtained and compared the corresponding values to Mori-Tanaka model as is depicted in Figure 13(a). It can be observed that the Micromechanics-based-model exhibits the same tendency than our results, representing a relatively good agreement with the numerical results for $\mathrm{SiO}_{2} \mathrm{Volumetric}$ fractions up to $34.1 \%$. The case when $\mathrm{R}=0 \mathrm{~m}^{2} \mathrm{KGW}^{-1}$ is shown in Figure S3 (Supplementary Material). Note that the thermal conductivity values, according to Mori-Tanaka model, are farther away when the concentration of $\mathrm{SiO}_{2}$ is $f>34.1 \%$ and $\mathrm{VO}_{2}$ is in the metallic phase. It indicates that the effect of the thermal resistance becomes significant at high volumetric fractions of $\mathrm{SiO}_{2}$. Therefore, from the results shown in Figures 8(b) and 13(a), it can be inferred that our numerical approach allows us to obtain accurate values of effective thermal conductivity for particulate composites, independently of the nature of the matrix.

A similar calculation as for the red curve in Figure 9 leads to a rate of decrease of the effective thermal conductivity of $8.6 \times 10^{-3} \mathrm{Wm}^{-}$ ${ }^{1} \mathrm{~K}^{-2}$. The heat flux profile is shown in Figure 13(b) for composite 2. In contrast to composite 1, the $2 \mathrm{D}$ profile corresponding to 
composite 2, the matrix can be seen as an "ocean" of $\mathrm{VO}_{2}$ while the circular particles act as "islands" of $\mathrm{SiO}_{2}$. Therefore, when the temperature difference is imposed on the composite, the heat is forced to flow through that "ocean" of $\mathrm{VO}_{2}$. When the thermal resistance is zero, the heat flow profile looks slightly brighter (see Figure S5 in Supplementary Material).
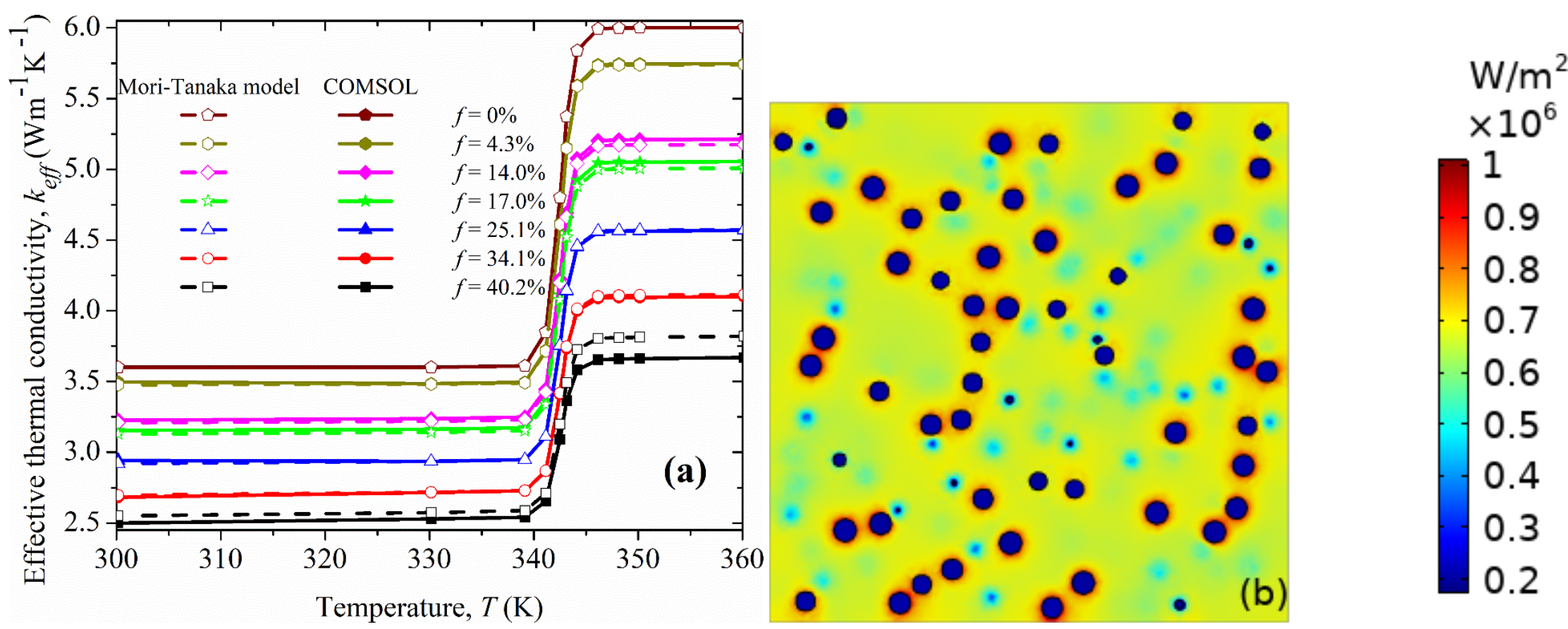

Figure 13. (a) Comparison between the predictions of numerical calculations of ETC for $R=0 \mathrm{~m}^{2} \mathrm{KGW}^{-1}$ (dashed lines) and $R=35$ $\mathrm{m}^{2} \mathrm{KGW}^{-1}$ (solid lines) for as a function of temperature. (b) Cut plane of the 3D thermal flux profile (front view) for composite 2, calculations were performed considering $r=1 \mu \mathrm{m}$ and $R=35 \mathrm{~m}^{2} \mathrm{KGW}^{-1}$.

\subsection{Validation method against the paraffin@ $@ \mathrm{VO}_{2} \mathrm{PCM}$}

Figure 14(b) depicts the mass fraction dependent thermal conductivity of the paraffin@ $\mathrm{VO}_{2} \mathrm{PCMs}$. With the increase of VO fraction in the shell, the effective thermal conductivity increase as is predicted also with our numerical calculations performed in $\mathrm{COMSOL}^{\mathrm{TM}}$ 
(red curve). The calculated values are slightly higher than the experimental data, we believe this is because we did not consider any thermal resistance value. However, the trend is in good agreement with the experiment.
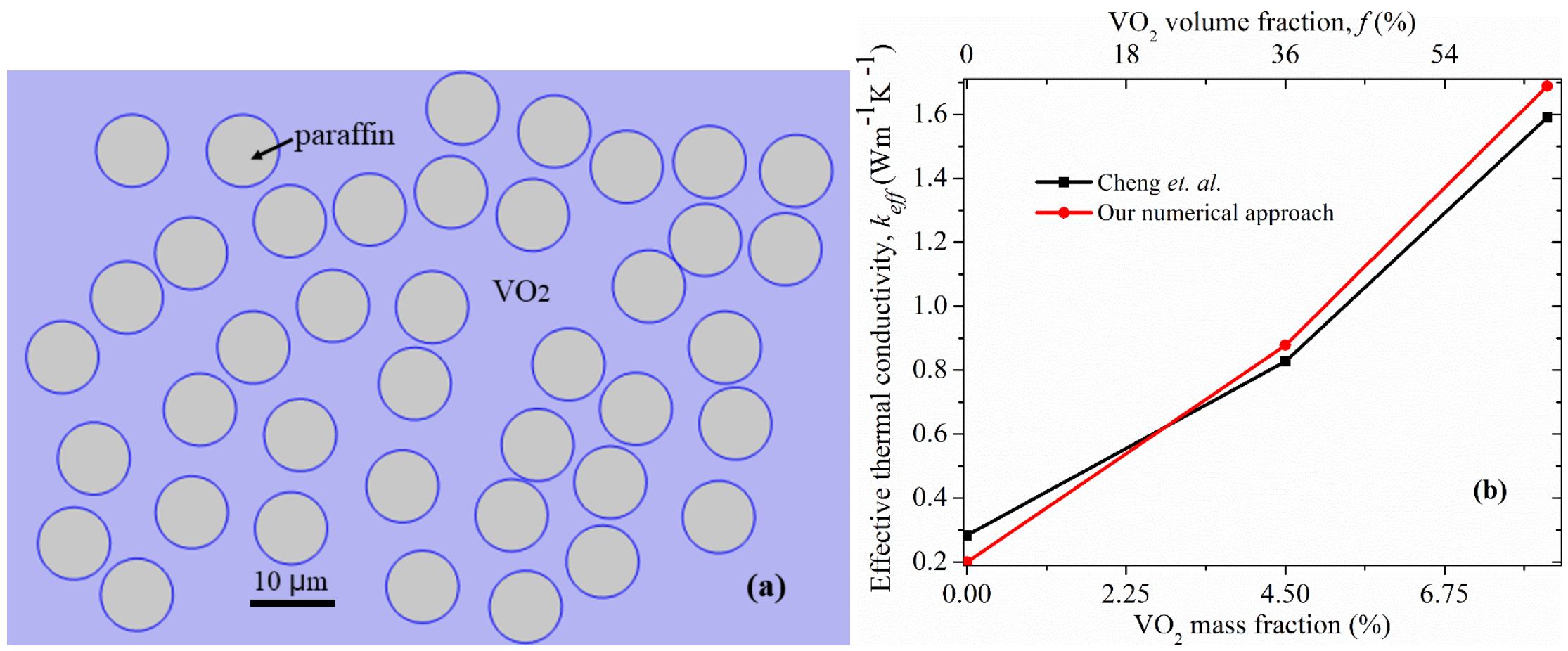

Figure 14. (a) $2 \mathrm{D}$ profile for paraffin particles embedded in a $\mathrm{VO}_{2}$ matrix. (b) Thermal conductivity of the paraffin@ $\mathrm{VO} 2 \mathrm{PCM}$ as a function of $\mathrm{VO}_{2}$ mass and volume fractions.

As well as the paraffin@ $\mathrm{VO}_{2} \mathrm{PCM}$, our $\mathrm{VO}_{2} / \mathrm{SiO}_{2}$ composite (theoretically) maintained high latent heat and largely improved thermal conductivity values ascribed to the thermal management properties of $\mathrm{VO}_{2}$.

\section{Conclusions}


We have studied numerically the effective thermal conductivity of composites made up of $\mathrm{VO}_{2}\left(\mathrm{SiO}_{2}\right)$ spherical particles randomly distributed and embedded in a $\mathrm{SiO}_{2}\left(\mathrm{VO}_{2}\right)$ matrix in a range of temperatures from $300 \mathrm{~K}$ to $360 \mathrm{~K}$. Three-dimensional finite element simulations have been performed for volume fractions up to $40.2 \%$ and for different sphere radii as well as various interface thermal resistance values. We have shown that: i) The effective thermal conductivity of $\mathrm{VO}_{2} / \mathrm{SiO}_{2}$ composites increases with the $\mathrm{VO} 2$ particles' size, while the one of $\mathrm{SiO}_{2} / \mathrm{VO}_{2}$ composites is pretty much independent of the $\mathrm{SiO}_{2}$ particles' radius. ii) At the $\mathrm{VO}_{2}$ transition temperature $(342.5 \mathrm{~K})$, the effective thermal conductivity of $\mathrm{VO}_{2} / \mathrm{SiO}_{2}$ composites increases significantly at a rate of $2.7 \mathrm{x}$ $10^{-3} \mathrm{Wm}^{-1} \mathrm{~K}^{-2}$, such that its value doubles up the $\mathrm{SiO}_{2}$ matrix thermal conductivity at the particle concentration of $40.2 \%$. While the effective thermal conductivity of $\mathrm{SiO}_{2} / \mathrm{VO}_{2}$ composites decreases at a rate of $8.6 \mathrm{x} 10^{-3} \mathrm{Wm}^{-1} \mathrm{~K}^{-2}$. iii) The effective thermal conductivity is strongly affected by the thermal resistance in $\mathrm{VO}_{2} / \mathrm{SiO}_{2}$ composites, by contrast the resistance effect does not play an important role for particle volume fractions of $\mathrm{SiO}_{2}$ up to $34.1 \%$ in $\mathrm{SiO}_{2} / \mathrm{VO}_{2}$ composites.

Our calculations of effective thermal conductivity are in good agreement with those of robust experiment for the paraffin@ VO $2 \mathrm{PCM}$ Thus, we can conclude that our numerical approach correctly predicts the effective thermal conductivity of composites made up $\mathrm{VO}_{2}$.

The latent heat of $\mathrm{VO}_{2} / \mathrm{SiO}_{2}$ composites increases with the $\mathrm{VO}_{2}$ particles' concentration, such that at $40.2 \%$, it takes the value of $24553 \mathrm{~J} \mathrm{~kg}^{-1}$ (486.7 $\mathrm{cal} \mathrm{mol}^{-1}$ ), which corresponds to $\sim 48 \%$ of the pure $\mathrm{VO}_{2}$. We suggest that our numerical approach can be used to provide an accurate way of predicting the effective thermal conductivity of composites, and it can be applied in guiding the design of phase change materials with modulated thermal conductivity and thermal energy storage capability. We also plan to extend our study to more complex geometries in order to know the effect of shape of the particles on the thermal properties of composites based on $\mathrm{VO}_{2}$.

\section{Acknowledgments}

One of the authors, S. Alvarez-Guerrero acknowledges a student fellowship from the Consejo Nacional de Ciencia y Tecnología (CONACyT, México). This work was partially supported by CONACyT-México under Grant No. 288344 and SRE-AMEXCID-2016$1-278320$ project.

\section{Data availability}

The data that support the findings of this study are available from the corresponding author upon reasonable request.

\section{References}


[1] N.L. Hancox, Engineering mechanics of composite materials, 1996. https://doi.org/10.1016/s0261-3069(97)87195-6.

[2] S. Chen, X. Yi, H. Ma, T. Xiong, H. Wang, C. Ke, Phase Transition VO2 Thin Films for Optical Switches, Int. J. Infrared Millimeter Waves. 25 (2004) 157-163. https://doi.org/10.1023/B:IJIM.0000012771.09884.61.

[3] J. Ordonez-Miranda, J.M. Hill, K. Joulain, Y. Ezzahri, J. Drevillon, Conductive thermal diode based on the thermal hysteresis of VO2 and nitinol, J. Appl. Phys. 123 (2018) 1-7. https://doi.org/10.1063/1.5019854.

[4] H. Nazir, M. Batool, F.J. Bolivar Osorio, M. Isaza-Ruiz, X. Xu, K. Vignarooban, P. Phelan, Inamuddin, A.M. Kannan, Recent developments in phase change materials for energy storage applications: A review, Int. J. Heat Mass Transf. 129 (2019) 491523. https://doi.org/10.1016/j.ijheatmasstransfer.2018.09.126.

[5] J. Pereira da Cunha, P. Eames, Thermal energy storage for low and medium temperature applications using phase change materials - A review, Appl. Energy. 177 (2016) 227-238. https://doi.org/10.1016/j.apenergy.2016.05.097.

[6] V.N. Andreev, F.A. Chudnovskii, A. V. Petrov, E.I. Terukov, Thermal conductivity of VO2, V3O5, and V2O3, Phys. Status Solidi. 48 (1978) K153-K156. https://doi.org/10.1002/pssa.2210480257.

[7] F.J. Morin, Oxides which show a metal-to-insulator transition at the neel temperature, Phys. Rev. Lett. 3 (1959) 34-36. https://doi.org/10.1103/PhysRevLett.3.34.

[8] Y.J. Chang, C.H. Koo, J.S. Yang, Y.S. Kim, D.H. Kim, J.S. Lee, T.W. Noh, H.T. Kim, B.G. Chae, Phase coexistence in the metal-insulator transition of a VO2 thin film, Thin Solid Films. 486 (2005) 46-49. https://doi.org/10.1016/j.tsf.2004.11.220.

[9] S. Chen, Z. Wang, H. Ren, Y. Chen, W. Yan, C. Wang, B. Li, J. Jiang, C. Zou, Gate-controlled VO2 phase transition for highperformance smart windows, ArXiv. (2018) 1-9.

[10] N. Manca, T. Kanki, F. Endo, D. Marré, L. Pellegrino, Planar Nanoactuators Based on VO2Phase Transition, Nano Lett. 20 (2020) 7251-7256. https://doi.org/10.1021/acs.nanolett.0c02638.

[11] H. Prod'homme, J. Ordonez-Miranda, Y. Ezzahri, J. Drévillon, K. Joulain, VO2-based radiative thermal transistor with a semitransparent base, J. Quant. Spectrosc. Radiat. Transf. 210 (2018) 52-61. https://doi.org/10.1016/j.jqsrt.2018.02.005.

[12] T. Cheng, N. Wang, H. Wang, R. Sun, C.P. Wong, A newly designed paraffin@VO2 phase change material with the combination of high latent heat and large thermal conductivity, J. Colloid Interface Sci. 559 (2020) 226-235. https://doi.org/10.1016/j.jcis.2019.10.033.

[13] K. Muramoto, Y. Takahashi, N. Terakado, Y. Yamazaki, S. Suzuki, T. Fujiwara, VO2-dispersed glass: A new class of phase change material, Sci. Rep. 8 (2018) 1-8. https://doi.org/10.1038/s41598-018-20519-6.

[14] D.P. Yu, Q.L. Hang, Y. Ding, H.Z. Zhang, Z.G. Bai, J.J. Wang, Y.H. Zou, W. Qian, G.C. Xiong, S.Q. Feng, Amorphous silica nanowires: Intensive blue light emitters, Appl. Phys. Lett. 73 (1998) 3076-3078. https://doi.org/10.1063/1.122677. 
[15] R. Lopez, L.A. Boatner, T.E. Haynes, L.C. Feldman, R.F. Haglund, Synthesis and characterization of size-controlled vanadium dioxide nanocrystals in a fused silica matrix, J. Appl. Phys. 92 (2002) 4031-4036. https://doi.org/10.1063/1.1503391.

[16] J.B. MacChesney, H.J. Guggenheim, Growth and electrical properties of vanadium dioxide single crystals containing selected impurity ions, Solid State Commun. 6 (1968) xxix-xxx. https://doi.org/10.1016/0038-1098(68)90594-2.

[17] J.B. Goodenough, The two components of the crystallographic transition in VO2, J. Solid State Chem. 3 (1971) $490-500$. https://doi.org/10.1016/0022-4596(71)90091-0.

[18] J.C. Maxwell, A treatise on electricity and magnetism, Oxford: Clarendon Press, 1873.

[19] Lord Rayleigh, Influence of Obstacles on the Properties of a Medium, Philos. Mag. Ser. 5. (1892) 37-41.

[20] D.P.H. Hasselman, L.F. Johnson, Effective Thermal Conductivity of Composites with Interfacial Thermal Barrier Resistance, J. Compos. Mater. 21 (1987) 508-515. https://doi.org/10.1177/002199838702100602.

[21] R. Pal, On the Lewis-Nielsen model for thermal/electrical conductivity of composites, Compos. Part A Appl. Sci. Manuf. 39 (2008) 718-726. https://doi.org/10.1016/j.compositesa.2008.02.008.

[22] K. Pietrak, T. Wiśniewski, A review of models for effective thermal conductivity of composite materials, J. Power Technol. 95 (2015) 14-24.

[23] O.P. Bruno, The effective conductivity of strongly heterogeneous composites, Proc. R. Soc. London. Ser. A Math. Phys. Sci. 433 (1991) 353-381.

[24] R. Lipton, Variational methods, bounds, and size effects for composites with highly conducting interface, J. Mech. Phys. Solids. 45 (1997) 361-384.

[25] H. Le Quang, Q.-C. He, G. Bonnet, Eshelby's tensor fields and effective conductivity of composites made of anisotropic phases with Kapitza's interface thermal resistance, Philos. Mag. 91 (2011) 3358-3392.

[26] J. Stránský, J. Vorel, J. Zeman, M. Šejnoha, Mori-Tanaka based estimates of effective thermal conductivity of various engineering materials, Micromachines. 2 (2011) 129-149.

[27] S. Lee, J. Lee, B. Ryu, S. Ryu, A micromechanics-based analytical solution for the effective thermal conductivity of composites with orthotropic matrices and interfacial thermal resistance, Sci. Rep. 8 (2018) 1-11.

[28] J. Ordonez-Miranda, Y. Ezzahri, K. Joulain, J. Drevillon, J.J. Alvarado-Gil, Modeling of the electrical conductivity, thermal conductivity, and specific heat capacity of VO2, Phys. Rev. B. 98 (2018) 1-7. https://doi.org/10.1103/PhysRevB.98.075144.

[29] D.W. Oh, C. Ko, S. Ramanathan, D.G. Cahill, Thermal conductivity and dynamic heat capacity across the metal-insulator transition in thin film VO2, Appl. Phys. Lett. 96 (2010). https://doi.org/10.1063/1.3394016. 
[30] V. Kuryliuk, A. Nadtochiy, O. Korotchenkov, C.C. Wang, P.W. Li, A model for predicting the thermal conductivity of SiO2Ge nanoparticle composites, Phys. Chem. Chem. Phys. 17 (2015) 13429-13441. https://doi.org/10.1039/c5cp00129c.

[31] R. Kothari, C.T. Sun, R. Dinwiddie, H. Wang, Experimental and numerical study of the effective thermal conductivity of nano composites with thermal boundary resistance, Int. J. Heat Mass Transf. 66 (2013) 823-829. https://doi.org/10.1016/j.ijheatmasstransfer.2013.07.061.

[32] L. Golubović, T.C. Lubensky, Nonlinear elasticity of amorphous solids, Phys. Rev. Lett. 63 (1989) 1082.

[33] F. Bédoui, J. Diani, G. Régnier, W. Seiler, Micromechanical modeling of isotropic elastic behavior of semicrystalline polymers, Acta Mater. 54 (2006) 1513-1523.

[34] M.M. G.Hur, T. Masaki, D.H. Yoon, Thermochromic properties of Sn, W Co-doped VO2 nanostructured thin film deposited by pulsed laser deposition, J. Nanosci. Nanotechnol. 14 (2014) 8941-8945. https://doi.org/10.1166/jnn.2014.10054.

[35] J. Jung, S. Lee, B. Ryu, S. Ryu, Investigation of effective thermoelectric properties of composite with interfacial resistance using micromechanics-based homogenisation, Int. J. Heat Mass Transf. 144 (2019) 118620.

[36] Z. Tong, M. Liu, H. Bao, A numerical investigation on the heat conduction in high filler loading particulate composites, Int. J. Heat Mass Transf. 100 (2016) 355-361. https://doi.org/10.1016/j.ijheatmasstransfer.2016.04.092.

[37] F.J. Ye, Z.G. Zeng, C. Lin, Z.Y. Hu, The investigation of electron-phonon coupling on thermal transport across metalsemiconductor periodic multilayer films, J. Mater. Sci. 50 (2014) 833-839. https://doi.org/10.1007/s10853-014-8643-Z.

[38] W. Zhou, S. Qi, C. Tu, H. Zhao, C. Wang, J. Kou, Effect of the particle size of Al2O3 on the properties of filled heat-conductive silicone rubber, J. Appl. Polym. Sci. 104 (2007) 1312-1318.

[39] G. Hamaoui, N. Horny, C.L. Gomez-Heredia, J.A. Ramirez-Rincon, J. Ordonez-Miranda, C. Champeaux, F. Dumas-Bouchiat, J.J. Alvarado-Gil, Y. Ezzahri, K. Joulain, M. Chirtoc, Thermophysical characterisation of VO2 thin films hysteresis and its application in thermal rectification, Sci. Rep. 9 (2019) 1-10. https://doi.org/10.1038/s41598-019-45436-0.

[40] Q. Zhang, Z. Pi, M. Chen, X. Luo, L. Xu, S. Liu, Effective thermal conductivity of silicone/phosphor composites, J. Compos. Mater. 45 (2011) 2465-2473. https://doi.org/10.1177/0021998311401105. 